\title{
Good news for the ageing beta cell
}

\author{
Aaron Bender • Andrew F. Stewart
}

Received: 10 October 2013 / Accepted: 29 October 2013 /Published online: 21 November 2013

(C) Springer-Verlag Berlin Heidelberg 2013

Keywords Beta cell $\cdot$ PI3-kinase $\cdot$ Proliferation $\cdot$ PTEN . Signalling $\cdot$ Survival

$\begin{array}{ll}\text { Abbreviations } \\ \text { GLP1 } & \text { Glucagon-like peptide-1 } \\ \text { GPCR } & \text { G-protein-coupled receptor } \\ \text { MAPK } & \text { Mitogen-activated protein kinase } \\ \text { MTOR } & \text { Mammalian target of rapamycin } \\ \text { PDGF } & \text { Platelet-derived growth factor } \\ \text { PDK1 } & \text { PIP }_{3} \text {-dependent kinase } \\ \text { PI3K } & \text { Phosphatidylinositol-3-kinase } \\ \text { PIP }_{2} & \text { Phosphatidylinositol-4,5-bisphosphate } \\ \text { PIP }_{3} & \text { Phosphatidylinositol-3,4,5-trisphosphate } \\ \text { PKB } & \text { Protein kinase B } \\ \text { PKC } & \text { Protein kinase C } \\ \text { PTEN } & \text { Phosphatase and tensin homologue } \\ \text { Raf } & \text { Rapidly accelerated fibrosarcoma } \\ \text { Ras } & \text { Rat sarcoma protein } \\ \text { Rheb } & \text { Ras homologue enriched in brain } \\ \text { TSC1/2 } & \text { Tuberous sclerosis proteins 1 and } 2\end{array}$

\section{The clinical problem}

All agree that marked reductions in absolute beta cell mass are associated with both types 1 and 2 diabetes. For this reason, there is great interest in identifying methods to create and/or expand functional human beta cells either in vivo or ex vivo for replacement therapy. Unfortunately, experimental induction of human beta cell proliferation has proven frustratingly difficult and, to date, no group has been able to induce human beta cells to proliferate at high rates in a therapeutically

A. Bender $\cdot$ A. F. Stewart $(\square)$

Diabetes, Obesity and Metabolism Institute, The Icahn School of

Medicine at Mount Sinai, Atran 5, 1 Gustave L. Levy Place,

Box 1152, New York, NY 10029, USA

e-mail: andrew.stewart@mssm.edu feasible manner. This is in contrast to rodent models, in which induction of robust proliferation and beta cell expansion has been accomplished using many different growth factors, nutrients, biologics, small molecule agonists and surgical/ physiological manoeuvres. Painfully, it has been very challenging to demonstrate that any of these can drive rapid expansion of human beta cells. In part, this no doubt reflects human-rodent interspecies differences, but it is also clear that much of this is also an age-related issue. Age is an important issue because most studies in rodent models are performed in juvenile animals (2-3 months of age, equivalent to early adolescence in humans), whereas the main source of human beta cells for research is from cadaveric pancreas donors in the $40-50$ year age range. For example, Teta et al have shown that an age-related decline in beta cell proliferation and responsiveness to mitogens occurs in rodents [1], similar to the agerelated loss of proliferation that starts in humans in early childhood [2-7]. Simply stated, it is easy to stimulate proliferation in juvenile rodent beta cells, but difficult in those from mice older than 14 months, and from humans older than $2-5$ years. Recently, we and others have been able to induce robust adult human beta cell proliferation using overexpression of cell cycle molecules and gene therapy approaches, but these are not readily translated to humans with diabetes [8-11]. Thus, there is an urgent need to understand signalling pathways and receptors upstream of the cell cycle molecules that control and can activate human beta cell replication [12]. From these several perspectives, one key message of the article by Yang and colleagues in this issue of Diabetologia is that marked beta cell replication can indeed be induced in very old mice [13]. But more on this later.

\section{Phosphatidylinositol-3-kinase signalling}

Phosphatidylinositol-3-kinase (PI3K) is a ubiquitously distributed lipid kinase [12-20] shown in green in Fig. 1. PI3K signalling is activated by many different kinds of upstream signals coming from the cell surface, exemplified by, but not 


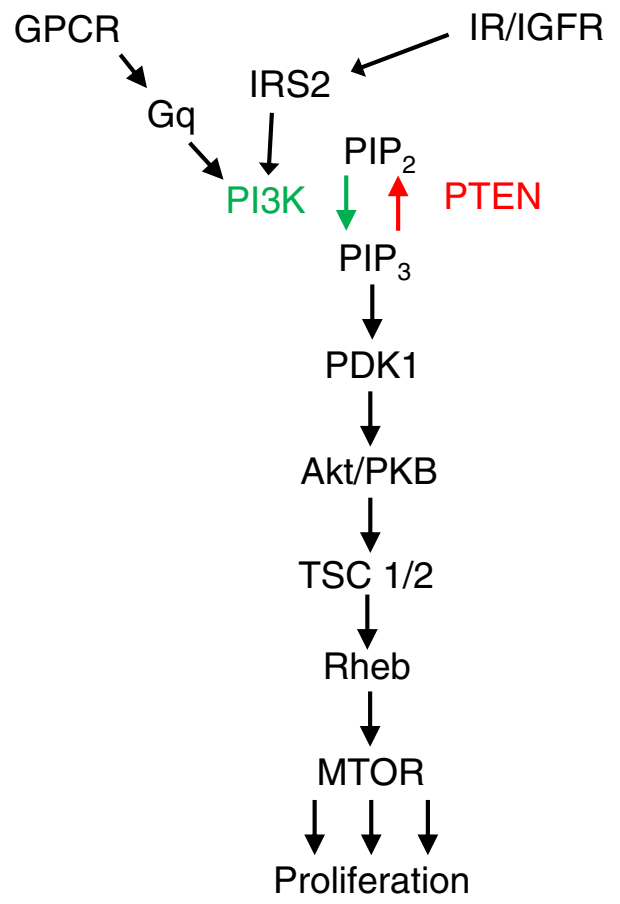

Fig. 1 The Yin and Yang of PI3K vs PTEN in the regulation of beta cell proliferation. This is a greatly oversimplified schematic of the receptor-toPI3K-to-proliferation pathway, focusing on PI3K (in green, because it activates the mitogenic pathway) and PTEN (in red because it inhibits the mitogenic pathway). In this example, a GPCR (such the GLP-1 receptor) activates PI3K via a G-protein (such as Gq); or a tyrosine kinase receptor, such as the insulin receptor (IR) or IGF-1 receptor (IGFR) activates PI3K via adaptor proteins, or in some cases directly. This leads to a sequence of downstream events including generation of $\mathrm{PIP}_{3}$, its activation of PDK1, which phosphorylates $\mathrm{Akt} / \mathrm{PKB}$, which in turn phosphorylates, thereby inhibiting, TSC1 and 2; this releases the small G-protein, Rheb, so that it can phosphorylate and activate MTOR. Active MTOR, through a complex series of downstream events, leads to proliferation. Not shown in the figure, this pathway interacts with a variety of other mitogenic and survival pathways, including, but not limited to, the Ras/Raf/MAPK pathways, Janus kinase/signal transducer and activator of transcription (JAK-STAT) signalling pathways and PKC signalling pathways. For readers who prefer more detail, Shi et al [17] provide illustrations of PTEN intracellular compartmentalisation and regulation of its levels and activity. In the context of the accompanying report by Yang et al [13], the key point is that PTEN is placed near the top of this pathway, and thus in a pivotal position for controlling the entire pathway. It balances the promitogenic activity of PI3K: its loss is permissive for increased activity in the pathway (and thus proliferation); conversely, its overexpression inhibits the pathway, reducing proliferation, and serving as a tumour suppressor protein (inhibiting proliferation)

limited to, tyrosine kinase receptors (such as the insulin and IGF-1 receptor), G-protein-coupled receptors (GPCRs; such as the glucagon-like peptide-1 (GLP-1)/exendin-4 receptor), and other classes of receptors. PI3K is linked to these cell surface receptors via molecules such as IRS2 and G-proteins. PI3K's enzymatic function converts phosphatidylinositol-4,5bisphosphate $\left(\mathrm{PIP}_{2}\right)$ to an active form, $\mathrm{PIP}-3,4,5$ trisphosphate $\left(\mathrm{PIP}_{3}\right)$, which then activates $\mathrm{PIP}_{3}$-dependent kinase-1 (PDK1). This in turn activates a downstream intracellular signalling cascade that includes a panoply of mitogenic, survival and cell size-enhancing molecules and their isoforms, such as Akt/ protein kinase B (PKB), Ras homologue enriched in brain (Rheb), tuberous sclerosis protein (TSC)1 and 2, mammalian target of rapamycin (MTOR) and ribosomal protein S6 kinase (p70S6K), among others. This is complex, but becomes more complex because 'PI3K' proves to be not one enzyme, but a large family of catalytic and regulatory subunits. In addition, the PI3K pathway is not linear, as shown in the simplified schema in Fig. 1, but crosstalks or intersects with other mitogenic/survival pathways, such as the rat sarcoma protein (Ras)/rapidly accelerated fibrosarcoma (Raf)/mitogen-activated protein kinase (MAPK) pathway, and various protein kinase $\mathrm{C}$ (PKC) pathways. These act in concert to drive cell cycle progression, to activate survival pathways, and to drive differentiation pathways, all in cell-type specific ways.

\section{PTEN}

This background serves to introduce the protein 'phosphatase and tensin homologue' (PTEN) (shown in red in Fig. 1) [12-20]. It is a negative regulator of PI3K activity by removing the 3-phosphate from $\mathrm{PIP}_{3}$. Through this mechanism PTEN is a tumour suppressor, the loss of which is linked to numerous cancer types, such as breast cancer. PTEN biology is also complex, as the protein is localised in both the nucleus and cytosol, and has an additional isoform derived from an alternative translational initiation site that generates a secretory form that can penetrate adjacent cells and suppress their proliferation $[15,16]$. In addition, PTEN itself is subject to complex transcriptional, translational, proteasomal and posttranslational regulation [17]. The important point here is that, since PI3K is composed of so many different isoforms and subtypes, it is difficult to silence each of these in concert. Thus, PTEN is useful in research terms because it serves as a general inhibitor of most or all PI3K isoforms. Conversely, its loss in cancer, or its intentional removal in mouse genetic models, as in the Yang report [13], serves as a general activator of PI3K activity.

\section{PTEN and the mouse beta cell}

Since PI3K activates mitogenic pathways, and since PTEN is an upstream suppressor of PI3K, it makes sense to hypothesise that loss of PTEN in the beta cell would cause increases in beta cell proliferation, survival, mass and function. This prediction has been shown to be true by the Kushner, Stiles and Woo research groups using insulin promoter-driven Cre or generalised Pten knockout models [18-21]. However, since PTEN was removed in embryonic life in these earlier models, it is possible that effects observed in adults were the result of developmental events. More specifically, it is not possible to 
know if the proliferation observed in young adults, initiated in fetal life, would occur if PI3K were activated in aged beta cells.

This is the focal point of the Yang paper in this issue of Diabetologia [13]. The authors demonstrate that Pten deletion, using a tamoxifen-regulated insulin promoter-Cre system that effectively silences Pten following tamoxifen administration, leads to activation of proliferation and to enhanced beta cell survival following administration of streptozotocin. Most importantly, they show that this can be induced not only in young mice at 3-4 months of age, but also when Pten expression is disrupted at 12 months of age; indeed the resultant proliferation continues up to 24 months of age. This is remarkable, for it is one of a very few examples of induction of proliferation in aged mouse beta cells. Along related lines, Saltpeter and colleagues used a parabiosis model, joining young (1-month-old) to old (8-month-old) mice, to demonstrate that the circulation of young mice contains a factor or factors that can induce proliferation of beta cells in old mice [22]; however, some would argue that the 8-month-old mice are not really 'aged'. Chen et al showed that platelet-derived growth factor (PDGF) receptor signalling can activate proliferation in older beta cells [23], but their model used lifelong, constitutive PDGF receptor overexpression beginning during pancreas development, so that it is not clear that 'normal' aged beta cells would respond with a proliferative response to PDGF signalling. Thus, a very important novel aspect of the Yang report is their demonstration that PTEN loss-beginning in aged animals - can activate proliferation in what all would agree are very adult beta cells.

This is important, because it means that age-associated beta cell cycle arrest is not irreversible: with appropriate stimulation, aged beta cells can be induced to re-enter the cell cycle. This highlights another important question: why is it that aged beta cells are so resistant to replication? Is it quiescence? Senescence? Terminal differentiation? Enforcement of the 'disallowed genes' principle [24]? And what do these terms specifically mean in the context of the beta cell? Depletion of cell cycle activators? Excessive activation of cell cycle inhibitors? Reversal or activation of promoter methylation in certain genes? Methylation, de-methylation, acetylation etc. of relevant histone tails? Loss of telomeres? Here, the Yang paper also provides some preliminary clues: the authors show that cyclins D1 and D2 can be activated, and key cell cycle inhibitors, such as p27cip and $\mathrm{p} 16^{\mathrm{INK} 4 \mathrm{a}}$, can be repressed in the aged mouse beta cell by PTEN loss. Interestingly, one of the histone methylases that represses $p 16^{I N K 4 a}$ transcription, enhancer of zeste homologue-2 (EZH2), is also activated by PI3K activation. More than 30 other cell cycle activators and inhibitors can regulate cell cycle progression, so it is not certain that the few candidates studied to date are the only ones - or even the most important ones - that mediate the PI3K activation of cell cycle progression. But collectively, they demonstrate that cell cycle inhibition is not irreversible in the aged beta cell, and also provide hope that other mitogenic signalling pathways may be able to engage cell cycle machinery.

\section{New questions raised}

Each advance in research raises additional questions. One question raised here relates to beta cell function: despite remarkable increases in beta cell proliferation and mass, the Pten -null mice are not hypoglycaemic. This is surprising, and may suggest that PI3K activation and/or proliferation induce de-differentiation of beta cells. Alternatively, it may suggest that, on a per-cell basis, each beta cell is appropriately downregulating its insulin secretion. This was not studied using markers or bioassays of beta cell differentiation, and can only be analysed unequivocally in a reversible model in which PTEN function can be restored, or PI3K activity otherwise attenuated. Further, since different mouse genetic models may have different phenotypes when studied on different backgrounds, is this a generalised phenomenon, or representative of all or most mouse strains?

Also unanswered is the question of which of the many catalytic or regulatory subunits in the PI3K family is responsible for the proliferation and enhanced survival? Similarly, since there is crosstalk among PI3K downstream pathways, which specific pathways mediate proliferation and survival in this model of PTEN loss? Another key question is, what upstream receptors for growth factors or nutrients might be the natural upstream mediators or activators of PI3K mitogenic signalling in adult islets?

\section{Back to the clinical problem}

Of course, the biggest questions are: what relevance does all this have to human beta cell replication, regeneration and survival, and how can it be leveraged to treat diabetes? The article by Yang and colleagues is silent on this issue. However, there are some indications that the PI3K pathway can drive human beta cell proliferation, even in adults. First, both Akt/

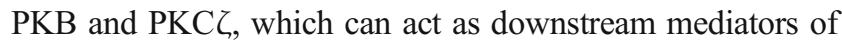
PI3K activation, can activate proliferation in adult human beta cells to a limited degree [25, 26]. Furthermore, human insulinoma has been associated with increases in cyclin D1 and cyclin-dependent kinase 4 (CDK4) [27, 28], and with inactivating mutations in TSC2 [29, 30], as well as in menin, which represses $p 18^{\mathrm{INK} 4}$ and $\mathrm{p} 27 \mathrm{cip}$ [31]. In addition, the Akt/ PKB inhibitor, tribbles homologue 3 , has been shown to repress proliferation in the human beta cell [32]. But most directly relevant to the Yang study and to human beta cell proliferation, there are at least two reports of PTEN mutations 
or deletions in pancreatic endocrine tumours [28, 29]. This contrasts with the Ras/Raf/MAPK pathway, which is commonly activated in pancreatic adenocarcinoma, but rarely, if ever, in insulinoma [28].

It is relatively easy to ask whether PI3K activation can drive human beta cell proliferation and survival. A more difficult question will be to identify the upstream ligands, receptors, and/or signalling molecules that should drive PI3K, but fail to, in adult human beta cells. These should be excellent targets for therapeutic induction of human beta cell proliferation, survival and function.

Acknowledgements The authors wish to thank A. Garcia-Ocaña, Icahn School of Medicine at Mount Sinai, New York, NY, USA, for his careful reading and helpful comments. We apologise to the many additional authors who have made important contributions to PTEN-PI3K and beta cell biology, but could not be cited because of space limitations.

Funding This work was funded by NIH/NIDDK grants R-01 DK 55023 and U-01 DK 089538 and by JDRF Grants 17-2011-598 and 342008-630.

Duality of interest The authors declare that there is no duality of interest associated with this manuscript.

Contribution statement Both authors were responsible for the conception and design of the manuscript, drafting the article and revising it critically for important intellectual content. Both authors approved the version to be published.

\section{References}

1. Teta M, Long SY, Wartschow LM, Rankin MM, Kushner JA (2005) Very slow turnover of beta-cells in aged adult mice. Diabetes 54 : 2557-2567

2. Meier JJ, Butler AE, Saisho Y et al (2008) Beta cell replication is the primary mechanism subserving the postnatal expansion of beta cell mass in humans. Diabetes 57:1584-1594

3. Kassem SA, Ariel I, Thornton PS, Scheimberg I, Glaser B (2000) Beta cell proliferation and apoptosis in the developing normal human pancreas and in hyperinsulinism of infancy. Diabetes 49:1325-1333

4. Gregg BE, Moore PC, Demozay D et al (2012) Formation of a human beta cell population within pancreatic islets is set early in life. J Clin Endocrinol Metab 97:3197-3206

5. Levitt HE, Cyphert TJ, Pascoe JL et al (2011) Glucose stimulates human beta cell replication in vivo in human islets transplanted into NOD-SCID mice. Diabetologia 54:572-582

6. Maedler K, Schumann DM, Schulthess F et al (2006) Aging correlates with decreased beta-cell proliferative capacity and enhanced sensitivity to apoptosis: a potential role for Fas and pancreatic duodenal homeobox-1. Diabetes 55:2455-2462

7. Gargani S, Thevenet J, Yuan JE et al (2013) Adaptive changes of human islets to an obesogenic environment in the mouse. Diabetologia 56:350-358

8. Cozar-Castellano I, Takane KK, Bottino R, Balamurugan AN, Stewart AF (2004) Induction of beta cell proliferation and retinoblastoma protein phosphorylation in rat and human islets using adenoviral delivery of cyclin-dependent kinase- 4 and cyclin $\mathrm{D}_{1}$. Diabetes 53 : 149-159
9. Fiaschi-Taesch NM, Bigatel TA, Sicari BM et al (2009) A survey of the human pancreatic beta cell G1/S proteome reveals a potential therapeutic role for Cdk-6 and cyclin $D_{1}$ in enhancing human beta cell replication and function in vivo. Diabetes 58:882-893

10. Fiaschi-Taesch NM, Salim F, Kleinberger J et al (2010) Induction of human beta cell proliferation and engraftment using a single G1/S regulatory molecule, cdk6. Diabetes 59:1926-1936

11. Fiaschi-Taesch NM, Kleinberger JW, Salim F et al (2013) Cytoplasmic-nuclear trafficking of G1/S cell cycle molecules and adult human beta cell replication: a revised model of human beta cell G1/S control. Diabetes 62:2460-2470

12. Kulkarni RN, Bernal-Mizrachi E, Garcia-Ocaña A, Stewart AF (2012) Human $\beta$-cell proliferation and intracellular signaling: driving in the dark without a roadmap. Diabetes 61:2205-2213

13. Yang K-T, Bayan J-A, Zeng N et al (2013) Adult-onset deletion of Pten increases islet mass and beta cell proliferation in mice. Diabetologia. doi:10.1007/s00125-013-3085-8

14. Rhodes CJ, White MF, Leahy JL, Kahn SE (2013) Direct autocrine actin of insulin on beta-cells: does it make physiological sense? Diabetes 62:2157-2163

15. Hopkins BD, Fine B, Steinbach N et al (2013) A secreted PTEN phosphatase that enters cells to alter signaling and survival. Science 341:399-402

16. Bassi C, Ho J, Srikumar T et al (2013) Nuclear PTEN controls DNA repair and sensitivity to genotoxic stress. Science 341:395-399

17. Shi Y, Paluch BE, Wang X, Jiang X (2012) PTEN at a glance. J Cell Sci 125:4687-4692

18. Kushner JA, Simpson L, Wartschow LM et al (2005) Phosphatase and tensin homolog regulation of islet growth and glucose homeostasis. J Biol Chem 280:388-393

19. Stiles BL, Kuralwalla-Martinez C, Guo W et al (2006) Selective deletion of PTEN in pancreatic beta cells leads to increased islet mass and resistance to STZ-induced diabetes. Mol Cell Biol 26:2772-2781

20. Zeng N, Yang KT, Bayan JA et al (2013) PTEN controls beta cell regeneration in aged mice by regulating cell cycle inhibitor p16INK4a. Aging Cell. doi:10.1111/acel.12132

21. Wang L, Liu Y, Lu SY et al (2010) Deletion of PTEN in pancreatic beta-cells protects against deficient beta cell mass and function in mouse models of type 2 diabetes. Diabetes 59:3117-3126

22. Saltpeter SJ, Khalaileh A, Weinberg-Corem N, Ziv O, Glaser B, Dor Y (2013) Systemic regulation of the age-related decline of pancreatic beta cell replication. Diabetes 62:2843-2848

23. Chen H, Gu X, Liu Y et al (2011) PDGF signaling controls age-dependent proliferation in pancreatic $\beta$-cells. Nature 478: 349-355

24. Schuit F, van Lommel L, Granvik M (2012) Beta cell-specific gene repression: a mechanism to protect against inappropriate or maladjusted insulin secretion? Diabetes 61:969-975

25. Rao P, Roccisana J, Takane KK et al (2005) Gene transfer of constitutively active Akt markedly improves human islet transplant outcomes in diabetic SCID mice. Diabetes 54:1664-1675

26. Vasavada RC, Wang L, Fujinaka Y et al (2007) Protein kinase C- $\zeta$ markedly enhances $\beta$-cell proliferation: an essential role in growth factor-mediated $\beta$-cell mitogenesis. Diabetes 56:2732-2743

27. Chung DC, Brown SB, Grahme-Cooke F et al (2000) Overexpression of cyclin D1 occurs frequently in human pancreatic endocrine tumors. J Clin Endocrinol Metab 85:4373-4378

28. Lindberg D, Hessman O, Akerstrom G, Westin G (2007) Cyclindependent kinase-4 (cdk4) expression in pancreatic endocrine tumors. Neuroendocrinology 86:112-118

29. Jiao Y, Shi C, Edil B et al (2011) DAXX/ATRX and mTOR pathway genes are frequently altered in pancreatic neuroendocrine tumors. Science 331:1199-1203

30. Missisaglia E, Dalai I, Barbi S et al (2009) Pancreatic endocrine tumors: expression profiling evidences a role for Akt-mTOR pathway. J Clin Oncol 28:245-255 
31. Karnick SK, Hughes CM, Gu X et al (2005) Menin regulates pancreatic islet growth by promoting histone methylation and expression of genes encoding p27kip1 and p18Ink4c. Proc Natl Acad Sci U S A 102:14659-14664
32. Liew CW, Bochenski J, Kawamori D et al (2010) The pseudokinase tribbles homologue 3 interacts with ATF4 to negatively regulate insulin exocytosis in human and mouse beta cells. J Clin Invest $120: 2876-2888$ 